\title{
ESTUDO DA ADSORÇÃO DO CORANTE BÁSICO AZUL DE METILENO POR CASCAS DE Eucalyptus grandis LIXIVIADAS
}

\author{
H. F. DE MARCHI ${ }^{1}$, T. N. SOEIRO ${ }^{1}$ e M. R. T. HALASZ ${ }^{1}$ \\ ${ }^{1}$ Faculdades Integradas de Aracruz, Departamento de Engenharia Química \\ E-mail para contato: humberto.fdemarchi@gmail.com / thatyanasoeiro@gmail.com \\ RESUMO - O uso de subprodutos agrícolas e florestais como adsorventes de \\ baixo custo é estudado, na atualidade, como uma alternativa aos processos de \\ tratamentos de resíduos industriais, sobretudo da indústria têxtil. $\mathrm{O}$ trabalho em \\ questão avaliou a influência da concentração do adsorvente e do tempo na \\ adsorção do corante azul de metileno por cascas lixiviadas de eucalipto da espécie \\ Eucalyptus grandis. Os ensaios de adsorção foram realizados para as \\ concentrações de 50, 75, 100 e $125 \mathrm{mg} / \mathrm{L}$ do corante azul de metileno, $1 \mathrm{~g}$ de \\ casca e $1,5,9,13,17,21$ e 25 min de agitação. Os resultados dos ensaios de \\ adsorção mostraram que a casca do Eucalyptus grandis pode ser utilizada como \\ adsorvente de baixo custo mediante lixiviação, sendo o resultado mais expressivo \\ o obtido para a concentração de $125 \mathrm{mg} / \mathrm{L}$ do corante azul de metileno. Tal \\ concentração, após $25 \mathrm{~min}$, foi reduzida para $0,93 \mathrm{mg} / \mathrm{L}$, apresentando uma \\ capacidade máxima de adsorção de $12,41 \mathrm{mg} / \mathrm{g}(\mathrm{mg}$ de adsorvato por $\mathrm{g}$ de \\ adsorvente).
}

\section{INTRODUÇÃO}

O setor têxtil é um dos mais antigos e tradicionais segmentos industriais. Caracteriza-se por um elevado consumo de água e geração de grandes volumes de efluentes líquidos, os quais apresentam altas concentrações de corantes (Vasques et al., 2011 apud Souza et al., 2013).

Estima-se que 10 a $20 \%$ do corante utilizado na etapa de tingimento são descartados ao final do processo de beneficiamento do tecido devido à fixação incompleta (Anliker, 1978 apud Guarantini; Zanoni, 2000). Os corantes são, em geral, substâncias que quando aplicadas a um material lhe conferem cor. Este resíduo, quando despejado em rios e lagos, afeta a absorção da luz pela flora e fauna aquática e contamina os mananciais, ameaçando o ecossistema (Guarantini; Zanoni, 2000).

Diversas tecnologias de tratamento desses resíduos são descritas na literatura (Cooper, 1995 apud Morais, 1996). Embora apresentem certa eficácia, o seu custo inicial de implantação e de operação são de tal modo elevados que não se tornam atrativos para a insdústria. A adsorção é um dos processos mais eficazes para o tratamento desses efluentes. $\mathrm{O}$ material convencional que se mostra eficaz no processo de adsorção é o carvão ativado (Yeh et al., 1993 apud Morais, 1996). No entanto o carvão ativado é avaliado, comercialmente, como tendo um alto custo (Antunes et al., 2010). 
A adsorção é um fenômeno físico de superfície no qual uma substância é extraída de uma fase e concentrada em outra. O material adsorvido é denominado adsorvato e o material onde ocorre a adsorção é denominado adsorvente (Morais, 1996).

Atualmente, diversas pesquisas estão sendo realizadas a fim de estudar o uso de resíduos industriais e vegetais como adsorventes de baixo custo (Antunes et al., 2010), como por exemplo, maçaroca do milho, bagaço de cana de açúcar, farelo de trigo, casca de amendoin, cascas de árvores etc (Michelsen et al., 1992 apud Morais, 1996).

À vista do exposto, o presente trabalho objetivou verificar a viabilidade da utilização da casaca de eucalipto da espécie Eucalyptus grandis na adsorção do corante básico azul de metileno bastante usado na indústria têxtil e estudar a influência da concentração do adsorvente e do tempo na adsorção.

\section{MATERIAIS E MÉTODOS}

\subsection{Preparo do adsorvente (Eucalyptus grandis)}

As cascas de Eucalyptus grandis foram coletadas em uma plantação localizada em Aracruz, Espírito Santo. Em seguida, foram acondicionadas em sacos plásticos opacos e levadas ao laboratório, onde foram reduzidas a pequenos fragmentos manualmente, moídas e peneiradas em um conjunto de peneiras. Durante os ensaios de adsorção foram utilizadas somente as cascas com granulometria inferior ou igual a $0,6 \mathrm{~mm}$.

Para determinar o $\mathrm{pH}$ da casca do eucalipto, $5 \mathrm{~g}$ foram pesadas e transferidas para um béquer $(250 \mathrm{~mL})$ contendo $96,5 \mathrm{~mL}$ de água destilada. Em seguida, agitou-se vigorosamente por 5 min e efetuou-se a leitura do $\mathrm{pH}$. O valor encontrado foi de 5,67.

\subsection{Preparo do adsorvato (azul de metileno)}

O corante foi preparado a partir de $1,0 \mathrm{~g}$ de azul de metileno em pó. A massa pesada foi diluída em água destilada num balão volumétrico de $1.000 \mathrm{~mL}$. As soluções utilizadas nos ensaios de adsorção foram obtidas a partir de diluições desta solução inicial. A análise do pH indicou um valor de 7,03.

Ensaios de absorção foram realizados em um espectrofotômetro da marca Spectrum, modelo SP-2000UV, a fim de se identificar o comprimento de onda de máxima absorbância do azul de metileno. O valor encontrado foi de $660 \mathrm{~nm}(2,045 \mathrm{uA})$. De posse desse comprimento de onda, determinou-se uma curva de calibração com o auxílio do Excel utilizando as concentrações de 5, 10, 15 e $20 \mathrm{mg} / \mathrm{L}$ do corante azul de metileno. A equação encontrada $y=0,1011 x$ apresentou um coeficiente de determinação $\left(R^{2}\right)$ igual a 0,9988 , o que indica que o modelo linear obtido descreve corretamente os valores observados.

\subsection{Ensaio de adsorção}

Para a realização dos testes, utilizaram-se $100 \mathrm{~mL}$ das soluções de 50, 75, 100 e 125 $\mathrm{mg} / \mathrm{L}$ de azul de metileno preparadas anteriormente. As soluções foram colocadas em contato com $1 \mathrm{~g}$ de casca em um béquer $(250 \mathrm{~mL})$ sob agitação constante ao longo de diversos 
tempos, a saber, $1,5,9,13,17,21$ e 25 min. Um esquema simplório dos ensaios realizados é mostrado na Figura 1.

Figura 1 - Esquema simplório dos ensaios de adsorção.

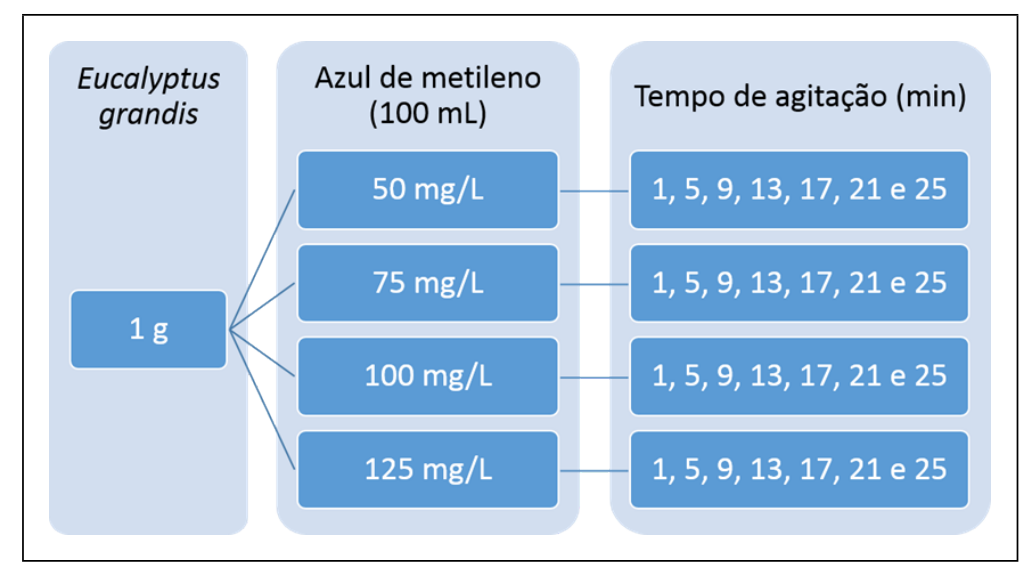

Após os ensaios, as soluções foram filtradas com o auxílio de um papel de filtro para determinação indireta de sua concentração por meio de um espectrofotômetro. Todos os testes foram realizados em triplicata para minimizar os erros de análise e diagnósticos.

\section{RESULTADOS E DISCUSSÕES}

Ensaios preliminares mostraram que ao colocar em contato a casca do Eucalyptus grandis e o corante azul de metileno, a coloração azul da solução do adsorvente se alterava imediatamente para verde, possivelmente devido a alguma interação. Dessa forma, optou-se por lixiviar a casca do Eucalyptus grandis conforme a ABNT NBR 10005:2004 antes dos ensaios de adsorção seguintes. Entretanto, mesmo após a lixiviação, percebeu-se que a alteração da coloração do adsorvente persistia. Diante disso, optou-se por ferver a casca do Eucalyptus grandis por $2 \mathrm{~h}$ após outra lixiviação.

Após os ensaios de adsorção, montaram-se as Tabelas 1, 2, 3 e 4.

Tabela 1 - Ensaio de adsorção para $50 \mathrm{mg} / \mathrm{g}$ do corante azul de metileno.

\begin{tabular}{cccc}
\hline $\begin{array}{c}\text { Concentração inicial } \\
(\mathrm{mg} / \mathrm{L})\end{array}$ & Tempo (min) & $\begin{array}{c}\text { Concentração final } \\
(\mathrm{mg} / \mathrm{L})\end{array}$ & $\begin{array}{c}\text { Corante adsorvido } \\
(\mathrm{mg} / \mathrm{g})\end{array}$ \\
\hline & 1,0 & 1,28 & 4,87 \\
& 5,0 & 0,76 & 4,92 \\
50,0 & 9,0 & 0,61 & 4,94 \\
& 13,0 & 0,52 & 4,95 \\
& 17,0 & 0,59 & 4,94 \\
& 21,0 & 0,66 & 4,93 \\
& 25,0 & 0,92 & 4,91 \\
\hline
\end{tabular}


A análise da Tabela 1 permite identificar que, para a solução de $50 \mathrm{mg} / \mathrm{L}$, houve uma diminuição da concentração de equilíbrio com o aumento do tempo até 13 min de agitação. A concentração obtida para esse tempo foi de $0,52 \mathrm{mg} / \mathrm{L}$. Após isso, houve um aumento da concentração final até $0,92 \mathrm{mg} / \mathrm{L}$ ( $25 \mathrm{~min})$. Já a quantidade de corante adsorvido manteve-se praticamente constante, variando entre 4,87 e $4,95 \mathrm{mg} / \mathrm{g}$. A maior quantidade de corante adsorvido em $\mathrm{mg} / \mathrm{g}$ se deu para o tempo de 13 minutos.

Tabela 2 - Ensaio de adsorção para $75 \mathrm{mg} / \mathrm{g}$ do corante azul de metileno.

\begin{tabular}{cccc}
\hline $\begin{array}{c}\text { Concentração inicial } \\
(\mathrm{mg} / \mathrm{L})\end{array}$ & Tempo (min) & $\begin{array}{c}\text { Concentração final } \\
(\mathrm{mg} / \mathrm{L})\end{array}$ & $\begin{array}{c}\text { Corante adsorvido } \\
(\mathrm{mg} / \mathrm{g})\end{array}$ \\
\hline & 1,0 & 4,89 & 7,01 \\
& 5,0 & 2,89 & 7,21 \\
75,0 & 9,0 & 2,51 & 7,25 \\
& 13,0 & 2,02 & 7,30 \\
& 17,0 & 1,83 & 7,32 \\
& 21,0 & 1,14 & 7,39 \\
& 25,0 & 0,75 & 7,43 \\
\hline
\end{tabular}

De acordo com a Tabela 2, para a solução de $75 \mathrm{mg} / \mathrm{L}$, houve uma diminuição da concentração com o decorrer do tempo. Após 25 min de agitação, a concentração da solução diminuiu de 75 para $0,75 \mathrm{mg} / \mathrm{L}$. Já a quantidade de corante adsorvido em $\mathrm{mg} / \mathrm{g}$ variou de 7,01 a 7,43 , sendo este último o valor máximo obtido

Tabela 3 - Ensaio de adsorção para $100 \mathrm{mg} / \mathrm{g}$ do corante azul de metileno.

\begin{tabular}{cccc}
\hline $\begin{array}{c}\text { Concentração inicial } \\
(\mathrm{mg} / \mathrm{L})\end{array}$ & Tempo (min) & $\begin{array}{c}\text { Concentração final } \\
(\mathrm{mg} / \mathrm{L})\end{array}$ & $\begin{array}{c}\text { Corante adsorvido } \\
(\mathrm{mg} / \mathrm{g})\end{array}$ \\
\hline & 1,0 & 2,22 & 9,78 \\
& 5,0 & 1,16 & 9,88 \\
& 9,0 & 0,98 & 9,90 \\
100,0 & 13,0 & 0,93 & 9,91 \\
& 17,0 & 0,96 & 9,90 \\
& 21,0 & 0,93 & 9,91 \\
& 25,0 & 0,88 & 9,91 \\
\hline
\end{tabular}

A análise da Tabela 3 permite identificar que, para a concentração de $100 \mathrm{mg} / \mathrm{L}$ do corante azul de metileno, houve uma diminuição da concentração final, ou seja, houve um aumento da quantidade absorvida pelo adsorvente, até 13 min de agitação. Após esse tempo, houve uma oscilação da concentração, atingindo o seu menor valor para o tempo de 25 min. Em relação a quantidade de corante adsorvido, o maior valor $(9,91 \mathrm{mg} / \mathrm{g})$ ocorreu para os 
tempos de 13, 21 e 25 minutos. Já o menor valor obtido foi de 9,78 mg/g para 1 minuto de agitação.

Tabela 4 - Ensaio de adsorção para $125 \mathrm{mg} / \mathrm{g}$ do corante azul de metileno.

\begin{tabular}{cccc}
\hline $\begin{array}{c}\text { Concentração inicial } \\
(\mathrm{mg} / \mathrm{L})\end{array}$ & Tempo (min) & $\begin{array}{c}\text { Concentração final } \\
(\mathrm{mg} / \mathrm{L})\end{array}$ & $\begin{array}{c}\text { Corante adsorvido } \\
(\mathrm{mg} / \mathrm{g})\end{array}$ \\
\hline & 1,0 & 5,42 & 11,96 \\
& 5,0 & 4,14 & 12,08 \\
125,0 & 9,0 & 2,90 & 12,21 \\
& 13,0 & 2,06 & 12,29 \\
& 17,0 & 1,92 & 12,31 \\
& 21,0 & 1,70 & 12,33 \\
& 25,0 & 0,93 & 12,41 \\
\hline
\end{tabular}

A análise da Tabela 4 permite identificar que, para a concentração de $125 \mathrm{mg} / \mathrm{L}$ houve uma redução linear significativa de todas as concentrações com o passar do tempo até 25 minutos de agitação. A quantidade de corante adsorvido variou de 11,96 a $12,41 \mathrm{mg} / \mathrm{g}$. A quantidade máxima de corante adsorvido $(12,41 \mathrm{mg} / \mathrm{g})$ se deu para 25 minutos.

\section{CONCLUSÃO}

O uso da casca do Eucalyptus grandis como adsorvente in natura não foi possível, uma vez que quando colocados em contato, adsorvato e adsorvente interagiam e alteravam a coloração da solução do adsorvente de azul para verde. A solução encontrada pelos autores foi lixiviar a casca do eucalipto por duas vezes de acordo com a NBR 10005:2004 e em seguida ferver a casca lixiviada por 2 horas em água destilada e sob agitação. Após estes procedimentos, pôde-se dar continuidade aos ensaios de adsorção.

Para todas as concentrações de azul de metileno avaliadas, houve um decréscimo rápido da concentração logo no primeiro minuto de agitação e com o decorrer do tempo até 25 min, não houve mais diminuições expressivas. Para a concentração de $50 \mathrm{mg} / \mathrm{L}$ do corante, a quantidade máxima adsorvida $(4,95 \mathrm{mg} / \mathrm{g})$ se deu para $13 \mathrm{~min}$ de agitação. Para a concentração de $75 \mathrm{mg} / \mathrm{L}$, foi preciso $25 \mathrm{~min}$ de agitação para que se atingisse o valor máximo de $7,43 \mathrm{mg} / \mathrm{g}$ de corante adsorvido. Já para a concentração de $100 \mathrm{mg} / \mathrm{L}$, somente 13 min de agitação foram necessários para que se atingisse a máxima adsorção $(9,91 \mathrm{mg} / \mathrm{g})$. Por fim, para a concentração de $125 \mathrm{mg} / \mathrm{L}$ do corante, a quantidade máxima adsorvida $(12,41$ $\mathrm{mg} / \mathrm{g}$ ) se deu para o tempo de 25 min de agitação.

A adsorção se revelou significativamente influenciada pelos dois parâmetros avaliados: concentração do corante e tempo de agitação. Entretanto, é possível observar por meio dos resultados obtidos que o efeito da concentração do corante foi maior do que o efeito do tempo de agitação. Exemplo disso são as quantidades de corantes adsorvidos por grama de casca determinados para as soluções de $50 \mathrm{mg} / \mathrm{L}$ e $125 \mathrm{mg} / \mathrm{L}$ do corante: 4,95 e 12,41 mg 
respectivamente. Os resultados mostraram que a adsorção foi maior em soluções cuja concentração de corante era maior.

\section{REFERÊNCIAS}

ANTUNES, L. M. P.; CAMARGO, S.R.G. de; JESUS, C. P. de; RUSSO, A.C. Estudo da utilização de serragem de madeira como adsorvente para tratamento de efluentes têxteis. Revista de Estudos Ambientais, v.12, n.2, p.7, 2010. Disponível em: <proxy.furb.br/ojs/index.php/rea/article/view/1697>. Acesso em: 27 de out. 2014.

ASSOCIAÇÃO BRASILEIRA DE NORMAS TÉCNICAS. NBR 10005: procedimento para obtenção de extrato lixiviado de resíduos sólidos. Rio de Janeiro, 2004.

GUARANTINI, C. C.; ZANONI, M. V. B. Corantes têxteis. Química Nova, v. 23, p. 75-76, 2000, São Paulo. Disponível em: <http://www.scielo.br/pdf/qn/v23n1/2146.pdf>. Acesso em: 27 out. 2014.

MORAIS, L. C. de P. Tratamento de efluentes têxteis simulados usando técnicas de adsorção. 1996. 122 f. p. 5, 6 e 10. Dissertação - Mestrado em Engenharia do Ambiente, Faculdade de Engenharia da Universidade do Porto. 1996.

SOUZA, K. C; ANTUNES, M. L. O, CONCEIÇÃO, F. T. da. Adsorção do corante Reativo Azul 19 em solução aquosa por lama vermelha tratada quimicamente com peróxido de hidrogênio. Química Nova, v.36, n.5, 2013, São Paulo. Disponível em: $<$ http://www.scielo.br/scielo.php?script=sci_arttext\&pid=S0100-40422013000500007>. Acesso em: 27 de out. 2014. 